\title{
A Cross Sectional Hospital Based Study of Antepartum Depression and its' Risk Factors
}

\author{
Mane Anupriya Suresh, Kadam Yugantara Ramesh*, Gore Alka Dilip, Dhumale Girish Bhimrao
}

\section{Mane Anupriya Suresh, Kadam Yugantara Ramesh*, Gore Alka Dilip, Dhumale Girish Bhimrao}

Department of Community Medicine, Bharati Vidyapeeth (Deemed to be University) Medical College and Hospital, Sangli, Maharashtra, INDIA.

\section{Correspondence}

Dr. Yugantara Ramesh Kadam

Professor, Department of Community Medicine, Bharati Vidyapeeth (Deemed to be University) Medical College and Hospital, Sangli, Maharashtra, INDIA Phone no: 02332212780

Email: yugakadam2011@gmail.com

\section{History}

- Submission Date: 18-04-2018

- Revised Date: 13-06-2018

- Accepted Date: 12-09-2018

DOI : 10.5530/ijmedph.2018.4.32

Article Available online

http://www.ijmedph.org/v8/i4

\section{Copyright}

(C) 2018 Phcog.Net. This is an openaccess article distributed under the terms of the Creative Commons Attribution 4.0 International license.

\begin{abstract}
Context and Aims: Antepartum depression in women is common and is of immense public health importance, as it can adversely affect both the mother and child; therefore it is necessary to identify women suffering from antepartum depression. The associated risk factors can be used for the screening to identify and manage the problem in time. This study was planned to evaluate women attending the hospital for Antepartum depression and to identify the probable risk factors. Methods and Materials: Pregnant mothers in second and third trimester coming for antenatal checkup Inclusion-criteria: All Antenatal women willing to participate in study. Exclusion-criteria- H/O any psychotic disorder, diabetes, any obstetric complication. Sample-size: 665, Sampling-Technique: Two stage sampling: Hospitals selected randomly. Purposive sampling for Study-subject. Study-duration: 6 months Study-tools: i. Edinburgh Postnatal Depression Scale [EPDS]. ii.Pre designed, pilot tested questionnaire. Results: There were 665 mothers with age ranging from 18 to38 years, mean 25.42 \pm SD 3.57. Possible depression (EPDS score $\geq 10$ ) was present in $71(10.7 \%)$ of mothers. Possible Depressionwas significantly high in age $34-38 y r s\left(33.3 \%, x^{2}=59.02, p=0.00\right)$, third gravida $\left(42.9 \%, x^{2}=83.516, p=0.000\right)$, mothers with $5-10$ std education $\left(20 \%, x^{2}=7.723, p=0.02\right)$, in employed women $(33.9 \%$, $\left.x^{2}=42.62, p=0.00\right)$, in mothers whose husbands with $5-10$ std education $\left(18.2 \%, x^{2}=16.98\right.$, $\mathrm{p}=0.000)$, in joint family type $\left(14.5 \%, x^{2}=6.917, \mathrm{p}=0.009\right)$, having previous female child $(92.9 \%$, $\left.x^{2}=71.626, p=0.000\right)$, financial constrains $\left(50 \%, x^{2}=6.52, p=0.011\right)$ and stressful life events $\left(71.4 \%, x^{2}=27.37, p=0.00\right)$. Strong Predictors of antenatal depression were employed mothers and female sex of previous child. Conclusion: Possible antepartum depression was common as nearly $11 \%$ of mothers were having EPDS score above or equal to 10 . Risk factors were previous female child and mother working as a employee.

Key words: Antepartum Depression, EPDS score, Risk factors for antepartum depression. Key Messages: Antenatal depression is common in antenatal women with risk factors like having a previous female child and employed mothers. Mothers with these strong predictors can be screened for possible depression and managed.
\end{abstract}

\section{INTRODUCTION}

Antenatal depression is related to child bearing that occurs during pregnancy. The antenatal period is a vulnerable period for the mother and her developing fetus. During this period, mother undergoes profound physiological and emotional changes. Depression in pregnancy may diminish one's capacity for self-care, including inadequate nutrition, poor antenatal clinic attendance. All of which may compromise a women's physical and mental health and may reduce optimal fetal monitoring or restrict the growth and development of the fetus. ${ }^{1-4}$ The immediate and long-term consequences of antenatal depression are far-reaching, affecting not only the mother but her infant, and their relationships.

New evidence shows that depression during pregnancy is associated with adverse child outcomes a study conducted in Boston. ${ }^{5,6}$

The prevalence of depression during the last trimester was found to be around $16 \%$ in a study conducted in USA by Marcus SM et al. ${ }^{7}$ According to Limlomwongse $\mathrm{N}$ et al. prevalence of antepartum depression was $20.5 \%$ in Thailand. ${ }^{8}$

A more recent study conducted on Southwestern Ethiopia found that the prevalence of depressive symptoms during pregnancy was $19.9 \%$ (95\% CI, 16.8-23.1), using EPDS scale. ${ }^{9}$

Some studies from south India have estimated prevalence rates of $9.8 \%$ and $17 \%$ respectively by Ajinkya S et al. ${ }^{10}$ and Mina $S$ et al. ${ }^{11}$

A systematic review has highlighted that life stress, lack of social support and domestic violence are significantly associated with increased risk of depression during pregnancy. ${ }^{12}$

Considering the adverse effects of antepartum depression it is worth to identify women suffering from it and manage them appropriately for avoiding its adverse outcome by arranging proper screening and planning for the treatment. However recent
Cite this article : Anupriya MS, Ramesh KY, Alka GD, Girish DB. A Cross Sectional Hospital Based Study of Antepartum Depression and Its' Risk Factors. Int J Med Public Health. 2018;8(4):158-62. 
Indian studies are few and that is why this study was proposed to find out hospital prevalence of antepartum depression and its risk factors. These risk factors will help for arranging screening of expectant mothers to identify presence of depression.

\section{SUBJECTS AND METHODS}

This was a hospital based, cross-sectional study, conducted from July 2016- December 2016 in Sangli-Miraj-Kupwad (SMK) Corporation area. After getting IEC clearance study was initiated. Study subjects were pregnant women in second and third trimester coming for antenatal check-up or admitted in ward. Women with H/O any psychotic disorder, diabetes, neurological disorder and obstetric complications were excluded from the study as these conditions results into anxiety and stress. Calculated sample size was 665 pregnant mothers $\left(\mathrm{p}=20.5 \%{ }^{10} \mathrm{q}=100-\mathrm{p}=79.5 \%\right.$, $\alpha=5 \%, d=15 \%$ ) by relative precision.

Two stage sampling technique was used for selection of study subjects. In the first stage a list of 2 medical colleges and all obstetrics hospitals (48) from SMK corporation area was prepared. One Medical college and two obstetrics hospitals were selected randomly. From these hospitals study subject were selected by purposive sampling technique; i.e. all eligible study subjects visiting selected hospitals during the study period were included. Half of the calculated sample size i.e. 333 subjects were enrolled from Medical College hospital and 166 each from two private hospitals.

Study tools: Study tool 1) Edinburgh Postnatal Depression Scale Questionnaire [EPDS]: For the assessment of antenatal depression EPDS scale was used and its availability is open. This scale is also validated for screening pregnant women for depression. ${ }^{13}$

The 10 question self-report scale (EPDS) is a valuable and efficient way of identifying patient's risk for antenatal depression. ${ }^{13}$ The EPDS is easy to administer and has proven to be an efficient screening tool. The Edinburgh Postnatal Depression Scale (EPDS) is the most widely used screening questionnaire for PPD (10). There are some studies where EPDS is used for screening of antepartum depression also..$^{13}$ In this scale women are asked to rate how they have felt in the previous 7 days. Maximum score of EPDS is 30. EPDS scale was translated in Marathi and back translated to English. This was done till we got best consensus between two questionnaires.

This Marathi version of EPDS was used.

\section{Case definition:}

1 Possible depression: score of $10-13$ on the scale indicates possible depression.

2 Depressive illness of varying severity: Mothers who scored 14 and above on the scale are likely to be suffering from depressive illness of varying severity. ${ }^{13}$

b) Proforma developed by investigators: The proforma was developed for collecting information on various risk factors with the help of experts and published literature. It was validated and pilot tested before using in the actual study.

Consent: (i) Permission for data collection was obtained from head of the department of Obs/gyn of medical college and private hospitals. (ii) Study subjects were explained about the purpose of data collection. After obtaining their written consent data was collected.

Data was collected by first investigator. For data collection privacy was provided to mothers by holding the data collection session in a separate room or by using curtains. Mothers were provided with EPDS questionnaire (Study tool 1) and after explaining it, mothers were asked to fill it up. For illiterate mothers data collection for EPDS scale was done by using interview technique. Study tool 2 was used as a interview schedule to collect the information from mothers.

\section{Data was entered in excel sheet}

Statistical Analysis: Analysis was done by using SPSS22 software (IBM Corp, Armonk, New York, USA). EPDS score was calculated for each study subject. Range, mean and SD was calculated for EPDS score and age. Percentages were calculated for different factors affecting EPDS score. Association between EPDS Score groups and socio-demographic factors and obstetric history was assessed by using chi-square test. Strong predictors were assessed by using binary logistic regression analysis. For this women with score $<10$ categorized as 'no depression' and score $\geq 10$ as 'possible depression' according to the EPDS.

Women with probable depression were referred to psychiatrist.

\section{RESULTS}

Total 665 mothers were screened for depression using the Edinburgh Postnatal Depression Scale. Their age ranged from 18 years to 38 years having mean of 25.42 and SD of 3.57. Majority of women were between 24 to 28 years, $(294,44.21 \%)$. Number of illiterate women was high i.e. 383 (57.59\%). Women with primary education were only $23(3.45 \%)$ i.e. up to $4^{\text {th }}$ standard. For analysis purpose they were combined with illiterate group, so total 406 women were included in illiterate group. Graduate women like B.A, B.Com, B.Ed., D.Ed., BE, B.Sc., M.Sc. were 159 (23.9\%). There were only $25(3.75 \%)$ women who have studied up to $11^{\text {th }}$ or $12^{\text {th }}$ std. These 25 women were combined with women with graduation for analysis purpose as there number was small. Occupation wise 556 (83.60\%) were housewives and 59 (8.87\%) mothers were employed. Mothers coming from rural area were 419 (63\%) and those residing in urban area were 246 (36.99\%).

Illiterate husbands were 339 (50.97\%) and 8 (1.2\%) had education up to primary school. Both were combined for analysis purpose making total 347 (52.18\%). About 159 (23.90\%) husbands had studied between $5^{\text {th }}$ to $10^{\text {th }}$ standard. Graduates were 140 like B.A, B.Com, B.Sc, IT, CS, CA, MBA, BBA, Engineer etc. and postgraduate. But there were only 19 husbands having education up to $11^{\text {th }}$ or $12^{\text {th }}$ standard. As this number was small they were combined with husbands with graduation and postgraduation for analysis purpose making total of 159 (23.90\%).

Maximum husbands were self-employed (314, 47.21\%) like shopkeepers and owners of garage, restaurants, doing business. Total 110 (16.54\%) husbands were in services like accountant, clerical job, professor etc. Total 241 (36.24\%) husbands were working as laborers, helpers or factory worker.

Mothers living in nuclear families were 396(59.54\%) and those living in joint families were 269 (40.45\%). There were 563(84.66\%) primigravida, $88(13.23 \%)$ second gravida and $14(2.10 \%)$ third gravida.

Out of $665,102(15.33 \%)$ mothers i.e. $2^{\text {nd }}$ gravida or $3^{\text {rd }}$ gravida had previous living child. Total 60 (9.02\%) mothers had previous male child, $28(4.21 \%)$ had one female child, $12(1.80 \%)$ had two previous female children and $2(0.30 \%)$ had one male and one female child previously.

Mode of delivery in 102 multigravid women was as follows: normal delivery in 52(50.98\%) and LSCS in 46 (45.09\%). Only 4 (3.92\%) women gave history of assisted delivery i.e. vaccum and forceps. For the purpose of analysis assisted deliveries were combined with normal vaginal delivery as the number was small.

Total 7 (1.05\%) mothers had experienced stressful life events like death of beloved $(3,0.45 \%)$, losing a job $(1,0.15 \%)$, ailing parents $(3,0.45 \%)$. Financial constraints were reported by $4(0.60 \%)$ mothers.

Out of 665 mothers total 71 mothers were depressed, from them possible depression was present in $69(10.37 \%)$ mothers (10-13EPDS score). Only $2(0.3 \%)$ mothers had score showing depressive illness of varying severity (14 and above EPDS score). As this number is very small for further analysis purpose they were included in possible depression. 


\begin{tabular}{|ccccc}
\multicolumn{5}{c}{ Table 1: Distribution of Study subjects according to Age and Gravidity. } \\
Age & $\begin{array}{c}\text { Primigravida } \\
\text { N (\%) }\end{array}$ & $\begin{array}{c}\text { Second } \\
\text { gravida } \\
\text { N (\%) }\end{array}$ & $\begin{array}{c}\text { Third } \\
\text { gravida N } \\
(\%)\end{array}$ & N (\%) \\
\hline 18-23yrs & $215(97.30)$ & $6(2.70)$ & $0(0.00)$ & $221(100.00)$ \\
$24-28 y r s$ & $264(89.8)$ & $29(9.90)$ & $1(0.3)$ & $294(100.00)$ \\
$29-33 y r s$ & $82(59.4)$ & $43(31.20)$ & $13(9.4)$ & $138(100.00)$ \\
$34-38 y r s$ & $2(16.7)$ & $10(83.30)$ & $0(0.00)$ & $12(100.00)$ \\
\hline Total & $563(82.40)$ & $88(13.20)$ & $14(2.1)$ & $665(100.00)$
\end{tabular}

Table 2: Association between Possible depression and socio-demographic factors.

\begin{tabular}{|c|c|c|c|c|}
\hline \multirow[b]{2}{*}{$\begin{array}{l}\text { Socio- } \\
\text { demographic } \\
\text { Factors }\end{array}$} & \multicolumn{2}{|c|}{ EPDS } & \multirow[b]{2}{*}{$\begin{array}{l}\text { Total } \\
\text { N (\%) }\end{array}$} & \multirow[b]{2}{*}{ Significance } \\
\hline & $\begin{array}{c}\text { No } \\
\text { Depression } \\
\mathrm{N}(\%)\end{array}$ & $\begin{array}{l}\text { Possible } \\
\text { Depression } \\
\text { N (\%) }\end{array}$ & & \\
\hline \multicolumn{5}{|c|}{ Age group } \\
\hline 19-23yrs & $203(91.9)$ & $18(8.1)$ & $221(100.0)$ & \multirow{5}{*}{$\begin{array}{c}\text { Chi square }=59.02 \\
\mathrm{P}=0.00\end{array}$} \\
\hline $24-28 y r s$ & $282(95.9)$ & $12(4.1)$ & $294(100.0)$ & \\
\hline $29-33 y r s$ & $101(73.2)$ & $37(26.8)$ & $138(100.0)$ & \\
\hline $34-38 y r s$ & $8(66.7)$ & $4(33.3)$ & $12(100.0)$ & \\
\hline Total & $594(89.3)$ & $71(10.7)$ & $665(100.0)$ & \\
\hline \multicolumn{5}{|c|}{ Mother's education } \\
\hline Up to $4^{\text {th }}$ std & $367(90.4)$ & $39(9.6)$ & $406(100.0)$ & \multirow{4}{*}{$\begin{array}{c}\text { Chi square }=7.723 \\
, P=0.021\end{array}$} \\
\hline $5-10^{\text {th }}$ & $60(80.0)$ & $15(20.0)$ & $75(100.0)$ & \\
\hline Above $10^{\text {th }}$ & $167(90.8)$ & $17(9.2)$ & $184(100.0)$ & \\
\hline Total & $594(89.3)$ & $71(10.7)$ & $665(100.0)$ & \\
\hline \multicolumn{5}{|c|}{ Mother's occupation } \\
\hline House wife & $512(92.1)$ & $44(7.9)$ & $556(100.0)$ & \multirow{7}{*}{$\begin{array}{c}\text { Chi } \\
\text { square }=42.620 \\
, P=0.000\end{array}$} \\
\hline Employed & $39(66.1)$ & $20(33.9)$ & $59(100.0)$ & \\
\hline self employed & $28(93.3)$ & $2(6.7)$ & $30(100.0)$ & \\
\hline labourer & $15(75)$ & $5(25)$ & $20(100.0)$ & \\
\hline Total & $594(89.3)$ & $71(10.7)$ & $665(100.0)$ & \\
\hline \multirow{2}{*}{\multicolumn{4}{|c|}{$\begin{array}{l}\text { Type of Family } \\
\qquad 32(8.1) \quad 396(100.0)\end{array}$}} & \\
\hline & $364(91.9)$ & & $396(100.0)$ & \\
\hline Joint & $230(85.5)$ & $39(14.5)$ & $269(100.0)$ & \multirow{2}{*}{$\begin{array}{c}\text { Chi } \\
\text { square }=6.917 \\
P=0.009\end{array}$} \\
\hline Total & $594(89.3)$ & $71(10.7)$ & $665(100.0)$ & \\
\hline
\end{tabular}

According to Table 1 In the age group 18-23 yrs, 97.3\% mothers were primigravid. While in $24-28$ yrs age group, $89.8 \%$ mothers were primigravid. In the age group $29-33$ yrs $59.4 \%$ mothers were primigravid. In the age group $34-38$ yrs $16.7 \%$ mothers were primigravid. (Table 1).

Possible depression was more in mothers in the age group 34-38 years (3.3\%) and significant association was seen between age of mothers and the EPDS score. (chi square $=59.02, \mathrm{P}=0.000$ ) (Table 2)

Twenty percent of mothers with possible depression were educated up to $5^{\text {th }}$ to $10^{\text {th }}$ standard thus mothers education was significantly associated with EPDS score. (Chi square=7.723, $\mathrm{P}=0.021$ ) (Table 2)
Occupation wise significantly more number of employed mothers $(20,33.9 \%)$ had possible depression than housewives. (Chi square $=42.620$, $\mathrm{P}=0.000$ ) (Table 2)

Possible depression was significantly more common in mothers whose husbands were educated up to $5^{\text {th }}$ to $10^{\text {th }}$ standard $(29,18.2 \%)$ thus husbands' education had shown a strong association with EPDS score. (chi square $=16.981, \mathrm{p}=0.000$ )

Possible depression was significantly more common in women whose husbands were working as employee $(16,14.5 \%)$, thus husbands occupation was not significantly associated with EPDS score. (Chi square $=3.372$, $\mathrm{P}=0.185$ )

Possible depression was significantly more common in mothers who lived in a joint family then those living in nuclear family. (Chi square $=6.917$, $\mathrm{P}=0.009$ ) (Table 2)

Possible depression increased as the gravidity increased,gravidity wise depression was more common in third gravida mothers $(6,42.9 \%)$ than second gravida $(31,35.20 \%)$ and primigravida $(34,6.0 \%)$ thus gravidity showed strong association with EPDS score. (chi square=83.516, $\mathrm{P}=0.000$ ) (Table 3)

Possible depression was present in $(26,92.9 \%)$ of mothers having a previous female child thus association of depression with sex of child was very strong. (Chi square $=71.626, \mathrm{P}=0.000$ ) (Table 3)

Possible depression was significantly more common in mothers having some stressful life events. Total 7 mothers had experienced stressful life events and from them 5(71.4\%) had possible depression. (Chi square $=27.379, \mathrm{P}=0.000$ )

Possible depression was significantly more common in mothers having financial constrains. Four mothers had financial constrains and from them 2 (50\%) had possible depression. (Chi square $=6.525, \mathrm{P}=0.011$ )

Mothers residing in rural or urban areas were not significantly associated with EPDS score. (Chi square=3.069, $\mathrm{P}=0.080$ )

Possible depression was not significant in mothers with history of chewing tobacco, two mothers gave history of chewing tobacco from which 1 (50\%) had possible depression. (Chi square $=3.253, \mathrm{P}=0.071$ )

Binary logistic regression analysis was done by backward Wald method to find out strong predictors of antenatal depression. For this all the variables having significant association with possible depression were used

\begin{tabular}{|c|c|c|c|c|}
\hline \multirow[b]{2}{*}{ Obstetric factors } & \multicolumn{2}{|c|}{ EPDS } & \multirow[b]{2}{*}{ Total N (\%) } & \multirow[b]{2}{*}{ significance } \\
\hline & $\begin{array}{c}\text { No } \\
\text { Depression } \\
\mathrm{N}(\%)\end{array}$ & $\begin{array}{l}\text { Possible } \\
\text { Depression } \\
\text { N (\%) }\end{array}$ & & \\
\hline \multicolumn{5}{|c|}{ Gravidity } \\
\hline Primigravida & $529(94)$ & $34(6)$ & $563(100.0)$ & \multirow{4}{*}{$\begin{array}{c}\text { Chi } \\
\text { square }=83.516 \\
P=0.000\end{array}$} \\
\hline Second gravida & $57(64.8)$ & $31(35.2)$ & $88(100.0)$ & \\
\hline Third gravida & $8(57.1)$ & $6(42.9)$ & $14(100.0)$ & \\
\hline Total & $594(89.3)$ & $71(10.7)$ & $665(100.0)$ & \\
\hline \multicolumn{5}{|c|}{ Sex of the previous child } \\
\hline Male & $55(91.70)$ & $5(8.30)$ & $60(100.0)$ & \multirow{5}{*}{$\begin{array}{c}\text { Chi } \\
\text { square }=71.626 \\
P=0.000\end{array}$} \\
\hline Female & $2(7.10)$ & $26(92.90)$ & $28(100.0)$ & \\
\hline Female, Male & $2(100.00)$ & $0(0.00)$ & $2(100.0)$ & \\
\hline Female, Female & $1(8.30)$ & $11(91.70)$ & $12(100.0)$ & \\
\hline Total & $60(58.80)$ & $42(41.20)$ & $102(100.0)$ & \\
\hline
\end{tabular}




\begin{tabular}{|c|c|c|c|c|c|c|c|c|}
\hline \multirow{2}{*}{ Predictors } & \multirow{2}{*}{ B } & \multirow{2}{*}{ S.E. } & \multirow{2}{*}{ Wald } & \multirow{2}{*}{ df } & \multirow{2}{*}{ Sig. } & \multirow{2}{*}{$\operatorname{Exp}(B)$} & \multicolumn{2}{|c|}{$95 \%$ C.I. for $\operatorname{EXP}(B)$} \\
\hline & & & & & & & Lower & Upper \\
\hline $\begin{array}{l}\text { Occupation } \\
\text { of Mother }\end{array}$ & 1.035 & 0.802 & 1.665 & 1 & 0.197 & 2.814 & 0.585 & 13.548 \\
\hline $\begin{array}{l}\text { Sex of } \\
\text { previous } \\
\text { Child }\end{array}$ & -5.056 & 0.801 & 39.827 & 1 & 0.000 & 0.006 & 0.001 & 0.031 \\
\hline Constant & 1.188 & 1.133 & 1.099 & 1 & 0.294 & 3.28 & & \\
\hline
\end{tabular}

$\mathrm{B}=$ Regression Coefficient, S.E. $=$ Standard Error, Wald $=$ Wald Coefficient, d.f. $=$ Degrees of freedom, Sig. $=$ significance, $\operatorname{Exp}(B)=$ Odds Ratio

like education of mother, education of husband, occupation of mother, gravidity and sex of the previous child. The strong predictor was sex of the previous child. (Table 4)

\section{DISCUSSION}

Depression during pregnancy has deleterious effects on both the foetus and the mother. It can easily be misattributed to normal physiological changes of pregnancy. Prevalence of depression in pregnancy ranges from $6 \%$ according to a study from USA conducted in year 2000 to $25 \%$ in a study conducted in Pakistan in 2003. ${ }^{14,15}$

To know the hospital prevalence of antepartum depression a cross sectional analytical hospital based study was conducted in Sangli-MirajKupwad Corporation area from June to December 2016.

In the present study overall hospital prevalence of depression was found to be $13.18 \%$ 'Possible depression' was found in 69 mothers $(10.37 \%)$. Only two (2.81\%) mothers had score showing depressive illness of varying severity. Some studies from south India have estimated prevalence rates of $9.8 \%$ and $17 \%$ respectively by Ajinkya $S$ et al. ${ }^{10}$ and Mina S et al. ${ }^{11}$

Most of the women (69.8\%) were in the age group of 18-24 years, which is in keeping with the sociocultural aspect of early marriage and childbirth in the Indian society.

Depression was found to be significantly more common in women with age of 34-38 years. Increasing age was also reported as an associated factor for anxiety and depression among pregnant women in a study conducted in Pakistan by A. Kazi, Z. Fatmi, et al. ${ }^{16}$

Possible depression was more common in working mothers or those who were employed. Housewives were relatively less depressed as compared to working mothers. Traditionally most of the Indian men don't contribute in household chores, whereas the women although working outside, doing some job even has to complete the household duties all alone creating a lot of workload to the mother in the pregnancy resulting stress. However a study from Bangalore, Karnataka conducted in 2006 concludes that housewives were more depressed than working women $(92.7 \%) .{ }^{13}$

Interestingly in present study it was found that mothers were significantly depressed when their husbands were in service than any other occupation.

In present study education of mother plays very important role in the possible depression as those mothers who are well educated mostly above $10^{\text {th }}$ Standard up to Postgraduates they showed very less depression as compared to mothers who are educated up to 10th standard only. Education changes attitude of mother towards the birth of the female child. Literate women are more likely to have good social networks and social support which has been identified as a protective factor in previous research studies. ${ }^{17-19}$ In contrast, a US-based study has highlighted education as a risk factor. ${ }^{20}$ Their husbands education is also equally important which is seen comparing to EPDS score where mothers whose husbands were more educated i.e. above $10^{\text {th }}$ Standard showed minimal depression compared to those husbands who are comparatively less educated. Education may be helpful in changing husband's attitude making them more considerate and supportive to wife. Thus education plays an important role for mother's mental status. Depression was significantly more common in multigravida i.e second or third gravida. Multigravids having previous female child were having depression more commonly and may be are expecting for a male child from the present pregnancy, and there is immense pressure on the mother regarding the outcome of this pregnancy. There is pressure on mothers to bare a male child, which is must. Primigravid women were less depressed as compared to third gravida, may be because primi were less worried about the gender of the child ${ }^{21}$ in comparison to multigravid mothers but possible anxiety and fear regarding delivery or the outcome of delivery may be the reason for presence of depression in the some of primigravid mothers. Presence of possible depression was associated with type of family of the mother. Where possible depression was present more commonly in mothers living in a joint family with her in laws .where she may be experiencing lot of pressure of the expectation of the in laws to have a male child. Financial difficulty was found to be significantly associated with depression. Similar findings were noted by other studies both in Asia and western countries. ${ }^{22,23}$

In the present study, gender of the child had played an important role in the presence of depression and it is the strong predictor. Majority of the women who had possible depression had previous female child. This shows that Indian society still prefer male child and there is great fear and anxiety present in the mothers regarding the outcome of the pregnancy. They have to deal with lot of pressure especially for a male child.

In a study in Turkey, which is a Muslim country in Western Asia, a baby boy is seen as a source of income. Women who cannot give birth to a baby boy may be considered incapable in the society; leading to serious problems in the marriage..$^{24}$ According to some study in India, the influence of boy preference has a major effect on mothers. The baby girl is viewed as a heavy economic drain on the family. This is partly due to the perception that most girls marry and thus contribute little economically to the family. The male child, on the other hand will one day be an earning member of the family. If women give birth to a baby girl, they are faced with a lack of support from their husband and in-laws leading to stress and depression. ${ }^{25}$

\section{CONCLUSION}

Possible antepartum depression was common as nearly $11 \%$ of mothers as their EPDS score was above or equal to 10. Main risk factor for antepartum depressionis presence of previous female child.

\section{Ethical considerations}

- After getting clearance from Institutional Ethical Committee data collection was started.

- Written consent was taken in vernacular language of the patient or study subject and written permission was sought from the in charge of selected hospitals.

- Those who were willing participated.

\section{CONFLICT OF INTEREST}

The authors declare no conflict of interest. 


\section{ABBREVIATIONS}

B.A: Bachelor of Arts; B.Com: Bachelor of Commerce; B.Ed.: Bachelor of Education; B.Sc.: Bachelor of Science; BBA: Bachelor of Business Administration; BE: Bachelor of Engineering; CA: Charted Accountant; CI: Confidence interval; CS: Computer Science; D.Ed.: Diploma of Education; EPDS: Edinburgh Postnatal Depression Scale; IEC: Institutional ethics Committee; IT: Information technology; LSCS: Lower section caesarean section; M.Com: Master of Commerce; M.Sc.: Master of science; MBA: Master of Business Administration; SD: Standard deviation; SPSS: Statistical package for social science; USA: United States of America.

\section{SUMMARY}

A Cross sectional analytical study was conducted in the antepartum women in second and third trimester attending hospitals for evaluation of depression using Edinburgh postpartum depression scale. Total 665 mothers were screened. Majority of women were in the age group of 2428 yrs and were primigravids. Possible antepartum depression was observed in $11 \%$ of mothers. Risk factors were previous female child and employed mothers.

\section{REFERENCES}

1. Austin MPV. Psychosocial assessment and management of depression and anxiety in pregnancy. Australian Family Physician. 2003;32(3):1-8.

2. Coverdale $\mathrm{JH}$, et al. Clinical implications and management strategies when depression occurs during pregnancy. Australian and New Zealand Journal of Obstetric Gynecology. 1996;36(4):424-9.

3. Wolkind S. Pre-natal emotional stress - effects on the fetus, in Pregnancy: A Psychological and Social Study Edited by: Wolkind S, Zajicek E. Academic Press: London. 1981.

4. Zuckerman B, et al. Depressive symptoms during pregnancy: Relationship to poor health behaviors. American Journal of Obstetrics and Gynecology. 1989;160(5):1107-11.

5. Zuckerman B, Amaro H, Bauchner $H$, Cabral H. Depressive symptoms during pregnancy: Relationshipto poor health behaviors. Am J Obstet Gynecol. 1989;160(5):1107-11.

6. Ryan D, Milis L, Misri N. Depression during pregnancy. Can Fam Physician. 2005;51(8):1087-93.

7. Marcus SM, Flynn HA, Blow FC, Barry KL. Depressive symptoms among pregnant women screened in obstetrics settings. J Womens Health (Larchmt). 2003;12(4):373-80.

8. Limlomwongse N, Liabsuetrakul T. Cohort study of depressive moods in Thai women during late pregnancy and 6-8 weeks of postpartum using the Edinburgh Postnatal Depression Scale (EPDS). Arch Womens Ment Health 2006;9(3):131-8.

9. Lau Y, Keung DW. Correlates of depressive symptomatology during the second trimester of pregnancy among Hong Kong Chinese. Soc Sci Med.
$2007 \cdot 64(6): 1802-11$

10. Ajinkya S, Jadhav PR, Srivastava NN. Depression during pregnancy: Prevalence and obstetric riskfactors among pregnant women attending a tertiary care hospital in Navi Mumbai. Ind Psychiatry J. 2013;22(1):37-40.

11. Mina S, Balhara YPS, Verma R, Mathur S. Anxiety and depression amongst the urban females of Delhi in Ante-partum and Post-partum period. Delhi Psychiatry J. 2012;15(2):347-51.

12. Lancaster CA, Gold KJ, Flynn HA, Yoo H, Marcus SM, Davis MM. Risk factors for depressive symptoms during pregnancy: a systematic review. American Journal of Obstetrics and Gynecology. 2010;202(1):5-14.

13. Bavle AD, Chandahalli AS, et al. Antenatal Depression in a Tertiary Care Hospital. Indian J Psychol Med. 2016;38(1):31-5.

14. DaCosta D, Larouche J, Dritsa M, Brender W. Psychosocial correlates of prepartum and postpartum depressed mood. J Affect Disord. 2000;59(1):31-40.

15. Rahman A, Iqbal Z, Harrington R. Life events, social support and depression in childbirth: Perspectives from a rural community in the developing world. Psychol Med. 2003;33(7):1161-7.

16. Kazi A, Fatmi Z, Hatcher J, Kadir MM, Niaz U, Wasserman GA. Social environment and depression among pregnant women in urban areas of Pakistan: importance of social relations. Social Science and Medicine. 2006;63(6):1466-76.

17. Dennis CL, Hodnett E, Kenton L, et al. Effect of peer support on prevention of postnatal depression among high risk women: multisite randomised controlled trial. British Medical Journal. 2009;338:280-3.

18. Francis L, Weiss BD, Senf JH, Heist K, Hargraves R. Does literacy education improve symptoms of depression and self-efficacy in individuals with low literacy and depressive symptoms? A preliminary investigation. Journal of the American Board of Family Medicine. 2007;20(1):23-7.

19. Weiss BD, Francis L, Senf JH, Heist K, Hargraves R. Literacy education as treatment for depression in patients with limited literacy and depression: a randomized controlled trial. Journal of General Internal Medicine. 2006;21(8):823-8.

20. Zimmerman FJ, Katon W. Socioeconomic status, depression disparities, and financial strain: what lies behind the income-depression relationship?. Health Economics. 2005;14(12):1197-215

21. Xie RH, Liao S, Xie H, Guo Y, Walker M, Wen SW. Infant sex, family support and postpartum depression in a Chinese cohort. J Epidemiol Community Health. 2011;65(8):722-6.

22. Rahman A, Creed F. Outcome of prenatal depression and risk factors associated with persistence in the first postnatal year: prospective study from Rawalpindi, Pakistan. J Affect Disord. 2007;100(1-3):115-6.

23. Horowitz JA, Goodman J. A longitudinal study of maternal postpartum depression symptoms. Res Theory Nurs Pract. 2004;18(2/3):149-63.

24. Rodrigues M, Patel V, Jaswal S, DeSouza N. Listening to mothers: qualitative studies on motherhood and depression from Goa, India. Soc Sci Med. 2003;57(10):1797-806

25. Dindar I, Erdogan S. Screening of Turkish women for postpartum depression within the first postpartum year: the risk profile of a community sample. Public Health Nurs. 2007;24(2):176-83 